\title{
Locus Coeruleus Phasic, But Not Tonic, Activation Initiates Global Remapping in a Familiar Environment
}

\author{
(DStephanie L. Grella, ${ }^{1}$ Jonathan M. Neil, ${ }^{2}$ Hilary T. Edison, ${ }^{2}$ Vanessa D. Strong, ${ }^{2}$ Irina V. Odintsova, ${ }^{1}$ Susan G. Walling, ${ }^{2}$ \\ Gerard M. Martin, ${ }^{2}{ }^{-D}$ Diano F. Marrone, ${ }^{1}$ and ${ }^{\circledR C}$ Carolyn W. Harley ${ }^{2}$ \\ ${ }^{1}$ Department of Psychology, Wilfrid Laurier University, Waterloo, Ontario N2L 3C5, Canada, and 2Department of Psychology, Memorial University of \\ Newfoundland, St. John's, Newfoundland A1B 3X9, Canada
}

Locus coeruleus (LC) neurons, the source of hippocampal norepinephrine (NE), are activated by novelty and changes in environmental contingencies. Based on the role of monoamines in reconfiguring invertebrate networks, and data from mammalian systems, a network reset hypothesis for the effects of LC activation has been proposed. We used the cellular compartmental analysis of temporal FISH technique based on the cellular distribution of immediate early genes to examine the effect of LC activation and inactivation, on regional hippocampal maps in male rats, when LC activity was manipulated just before placement in a second familiar (A/A) and/or novel environment $(\mathrm{A} / \mathrm{B})$. We found that bilateral phasic, but not tonic, activation of LC reset hippocampal maps in the A/A condition, whereas silencing the LC with clonidine before placement in the A/B condition blocked map reset and a familiar map emerged in the dentate gyrus, proximal and distal CA1, and CA3c. However, CA3a and CA3b encoded the novel environment. These results support a role for phasic LC responses in generating novel hippocampal sequences during memory encoding and, potentially, memory updating. The silencing experiments suggest that novel environments may not be recognized as different by dentate gyrus and CA1 without LC input. The functional distinction between phasic and tonic LC activity argues that these parameters are critical for determining network changes. These data are consistent with the hippocampus activating internal network representations to encode novel experiential episodes and suggest LC input is critical for this role.

Key words: contextual representations; hippocampus; immediate early genes; locus coeruleus; norepinephrine; remapping

\section{Significance Statement}

Burst activation of the broadly projecting novelty signaling system of the locus coeruleus initiates new network representations throughout the hippocampus despite unchanged external environments. Tonic activation does not alter network representations in the same condition. This suggests differences in the temporal parameters of neuromodulator network activation are critical for neuromodulator function. Silencing this novelty signaling system prevented the appearance of new network representations in a novel environment. Instead, familiar representations were expressed in a subset of hippocampal areas, with another subset encoding the novel environment. This "being in two places at once" argues for independent functional regions within the hippocampus. These experiments strengthen the view that internal states are major determinants of the brain's construction of environmental representations.

\section{Introduction}

Inspired by evidence from invertebrates that neuromodulators act to enhance adaptive behavior by rapidly reorganizing neural

\footnotetext{
Received July 31, 2018; revised Nov. 13, 2018; accepted Nov. 16, 2018.

Author contributions:S.L.G., J.M.N., H.T.E., V.D.S., and C.W.H. wrote the first draft of the paper; S.L.G., D.F.M., and C.W.H. edited the paper; S.L.G., G.M.M., D.F.M., and C.W.H. designed research; S.L.G., J.M.N., H.T.E., V.D.S., I.V.O., and D.F.M. performed research;S.L.G., S.G.W., G.M.M., and D.F.M. analyzed data; S.L.G. and C.W.H. wrote the paper.

This work was supported by Natural Sciences and Engineering Research Council Grants to S.L.G., G.M.M., D.F.M., and C.W.H.; and an Ontario Mental Health Foundation Grant to D.F.M. We thank Dr. Noam Miller, Dr. Nathen Insel, Dr. Bruce McKay, and Dr. Scott Ramsay for comments, technical editing, and proofreading of the article.

The authors declare no competing financial interests.

Correspondence should be addressed to Dr. Stephanie L. Grella, Department of Psychology, Wilfrid Laurier University, 75 University Avenue, Waterloo, Ontario N2L 3C5, Canada. E-mail: Grel0810@mylaurier.ca.
}

circuits, Bouret and Sara (2005) proposed "phasic activation of noradrenergic neurons of the locus coeruleus (LC) in time with cognitive shifts could provoke or facilitate dynamic reorganization of target neural networks, permitting rapid behavioral adaptation to changing environmental imperatives."

Here we examined projections from the LC, a structure involved in vigilance and novelty detection, to the hippocampus (HPC), which is proposed to play a major role in forming environmental representations (Hirsh, 1974; O'Keefe and Nadel, 
1978). Dynamics of ensemble encoding here may provide insight into mnemonic processes driving cognition and behavior. Relatively stable, these representations are reactivated when placed in a familiar environment; however, new spatial information creates conditions conducive to synaptic modification (Wilson and McNaughton, 1993). These representations must be malleable to truly exhibit adaptive behavior and an inability to integrate new information into the code may play a role in the etiology of posttraumatic stress disorder, a disorder characterized by a dysfunctional norepinephrine (NE) system (Hendrickson and Raskind, 2016).

Bouret and Sara's (2005) "network reset" hypothesis suggests that focused task performance is associated with low tonic LC activity with phasic burst activation occurring during behavioral shifts. Bursts occur when novel stimuli are encountered, with salient environmental changes, and with preparatory signals when new behavior is required (Bouret and Sara, 2005). Decreased LC firing reduces both behavioral and neural transitions. We have shown two HPC changes with glutamatergic LC activation (Brown et al., 2005): (1) increased theta power and (2) silencing of feedforward dentate gyrus (DG) interneurons. Glutamatergic LC activation also promotes HPC plasticity (Walling and Harley, 2004). Therefore, our in vivo data are consistent with LC network reset, with phasic activation suggesting adaptive promotion of novel encoding sequences for new episodes and updating of earlier sequences. Tonic activation also increases NE, and in the Bouret and Sara (2005) account, may also trigger reset.

Wagatsuma et al. (2018) revealed a crucial LC role in creating spatial representations by optogenetically silencing LC cell bodies and LC fibers in CA3 during the first experience in a new environment. Calcium imaging demonstrated that stable spatial maps did not form if LC input to CA3 was silenced during novel context exposure. Consistent with this, animals demonstrated behavioral impairments. We sought to determine how phasic and tonic LC activation shapes hippocampal contextual representations by activating LC during the second, rather than the first, environmental encounter and asked whether this produces an internal novelty signal, despite stability of external input, thus initiating remapping. We pharmacologically activated the LC immediately before the second exposure to a familiar environment (to induce remapping) and inactivated the LC before entering a second novel environment (to block remapping).

We used cellular compartmental analysis of temporal FISH in six hippocampal subregions. First (Experiment 1), we replicated effects of familiar (A/A) and novel (A/B) environmental exposures on immediate early gene (IEG) map profiles (Guzowski et al., 1999). These profiles were used as templates for categorizing familiar and novel maps. Initially, we induced phasic LC activation ipsilaterally using unilateral glutamate infusions before placement in the second environment. Next (Experiment 2), we bilaterally infused phasic or tonic LC activators using only the A/A condition such that the second environment should be mapped as familiar unless the LC salience signal led to remapping. Finally (Experiment 3), we inactivated the LC bilaterally with clonidine and examined representations in both novel and familiar second environments.

\section{Materials and Methods}

Animals. Male Sprague Dawley rats (Experiment 1) from the Vivarium Breeding Facility (Memorial University of Newfoundland) or male Long-Evans rats (Experiments 2 and 3) from Charles River Quebec were obtained at 2 months of age. Rats were kept on a reverse 12:12 h light/ dark cycle with ad libitum access to food and water. Each rat was handled for $15 \mathrm{~min} / \mathrm{d}$ for $6 \mathrm{~d}$ under red light. All handling for Sprague Dawley rats occurred before surgery, whereas Long-Evans rats were given $2 \mathrm{~d}$ of handling before surgery and then $4 \mathrm{~d}$ following surgery. Sprague Dawley rats were undisturbed for the 4 postsurgical days. Behavioral handling, surgery, and testing were performed by the same individual(s) for a given experiment: Experiment 1, H.T.E.; Experiment 2, J.M.N., Experiment 3, V.D.S./S.L.G. The results reported are based on data from a total of 81 experimental animals. All procedures were approved by the Memorial University Institutional Animal Care Committee and performed in accordance with the guidelines of the Canadian Council on Animal Care.

Cannulae implantation and drug microinjections. Animals were anesthetized with a chloral hydrate solution ( $1 \mathrm{ml}$ of $40 \mathrm{mg} / \mathrm{ml} / 100 \mathrm{~g}$ i.p.) for Experiment 1 or, for Experiments 2 and 3, with 5\% isoflurane and 70\% oxygen (for induction) with maintenance at $2 \%-3 \%$ isoflurane. An injection of meloxicam $(0.25 \mathrm{mg} / \mathrm{ml}$ at $0.2 \mathrm{mg} / \mathrm{kg}$, s.c.) was administered for analgesia. Aseptic surgeries were performed stereotaxically with skull flat. A unilateral 26 -gauge cannula $(7.7 \mathrm{~mm}$, Plastics One $)$ was directed at the left LC in Experiment 1 for glutamate-infused rats. Bilateral cannulae were implanted in Experiments 2 and 3 for control and drug infusions. LC coordinates were anteroposterior $-11.8 \mathrm{~mm}$, mediolateral $\pm 1.3 \mathrm{~mm}$, relative to bregma, dorsoventral $-5.5 \mathrm{~mm}$ from dura). Cannulae were angled 20 degrees posterior from the vertical plane. Obdurators that extended $1 \mathrm{~mm}$ below the pedestal were screwed into the cannulae to ensure patency.

Testing began $4 \mathrm{~d}$ after surgery. For Experiments 1 and 2, L-glutamate (GLUT, $500 \mathrm{~mm}$ in Experiment 1; $200 \mathrm{~mm}$ in Experiment 2) was used for phasic activation. Glutamate produces a brief $300-500 \mathrm{~ms}$ increase in LC firing followed by several minutes of LC silence (Harley and Sara, 1992). Baseline levels of firing reappear after this silence. There is no evidence of rebound excitation. Unilateral glutamate has previously been shown to initiate NE-mediated LTP of perforant path input to the ipsilateral DG (Harley, 2007; Reid and Harley, 2010) and a transient silencing of feedforward interneurons (Brown et al., 2005). This unilateral NE-LTP also occurs in awake rats (Walling and Harley, 2004). These effects of increased network plasticity and transient disinhibition support a model of changing network configurations in the DG. Therefore, we predicted that unilateral glutamate LC activation before placement in a familiar environment would result in global DG remapping in Experiment 1. Mechanical injector insertion in LC has also been shown to massively activate LC (Stone et al., 1995), but we have not previously tested this condition in plasticity experiments. We have also not tested unilateral glutamate LC effects in pyramidal cell regions.

In Experiment 2, all drugs were delivered bilaterally, and three tonic activators were chosen in addition to the phasic activator, glutamate: (1) the cholinergic muscarinic receptor activator, bethanechol $(\mathrm{BETH}$, $5 \mathrm{~mm}$ ), (2) the orexinergic activator, orexin A (ORX-A, $100 \mathrm{~nm}$ ), and (3) corticotropin releasing factor (CRF,100 nM). Each has been shown to induce increases in LC neuronal firing in previous reports as follows: For $\mathrm{BETH}$, the maximal increase to an infused bolus occurs in the first postinfusion minute, which is sustained for $2-3$ additional minutes and then gradually declines to baseline over 10-15 min (Berridge and Foote, 1991). For ORX-A, bolus LC ORX-A infusions similar to those used here produce an indirect index of LC firing, muscle tone facilitation, within 3 min of infusion, that is sustained for $9 \mathrm{~min}$. Fourth ventricle ORX-A activates both LC firing and muscle tone facilitation (Kiyashchenko et al., 2001). We have also shown that this bolus LC ORX-A infusion increases hippocampal NE for $10 \mathrm{~min}$ after infusion (Walling et al., 2004). CRF bolus microinfusions maximally increase firing during, and for several minutes after infusion, with activation gradually declining over $30 \mathrm{~min}$ (Curtis et al., 1997).

In Experiment 2, due to freezer failure, pyramidal cell sections for each of three brains were lost for analysis.

For Experiment 3, clonidine ( $3.75 \mathrm{~mm}$ ) was used to silence the LC.

All drugs were dissolved in a $1 \%$ methylene blue solution made up with aCSF ( $147 \mathrm{~mm} \mathrm{NaCl}, 3 \mathrm{~mm} \mathrm{KCl}, 1 \mathrm{~mm} \mathrm{MgCl}_{2}$, and $1.3 \mathrm{~mm} \mathrm{CaCl}_{2}$ ) in sterile water to permit localization of the infusions. Infusions were 200 $\mathrm{nl} /$ side for all drugs, except CRF, for which $300 \mathrm{nl} /$ side was used. Infusions were made using Hamilton gas tight syringes connected to 33 gauge injector cannulae that extended $1 \mathrm{~mm}$ below the outer cannulae. 
A

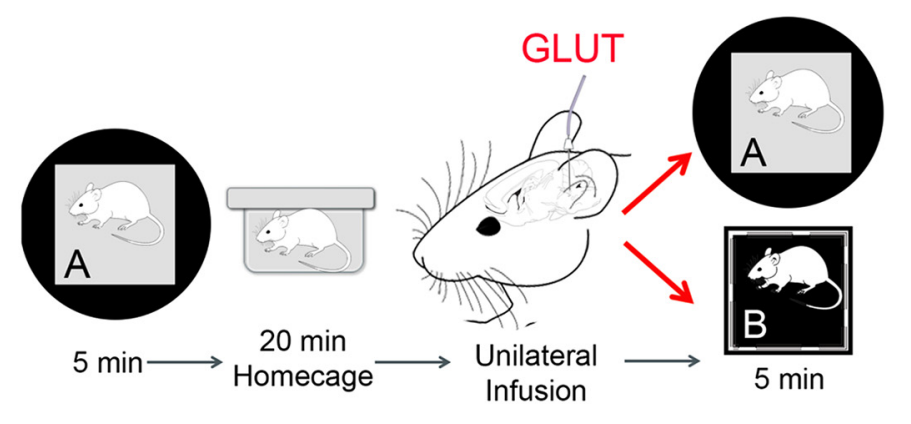

E

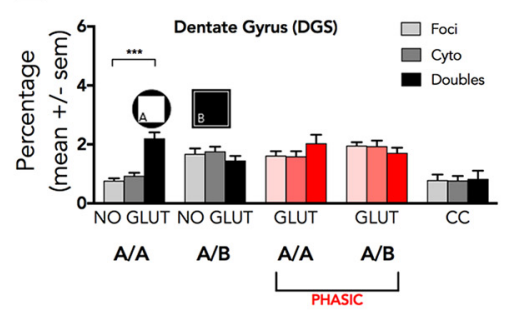

H

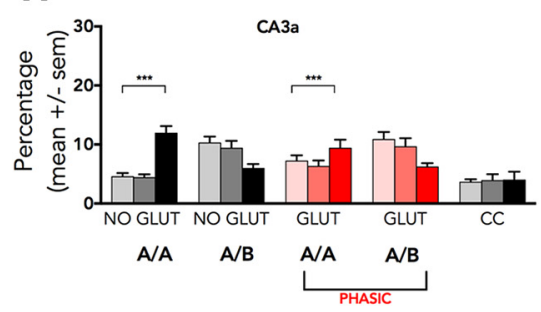

B

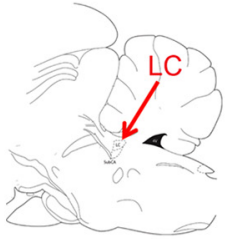

C

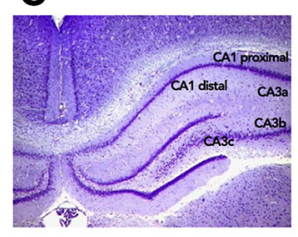

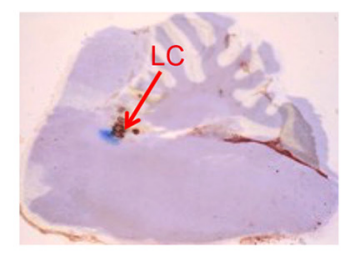

D

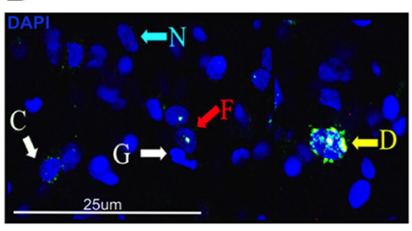

F

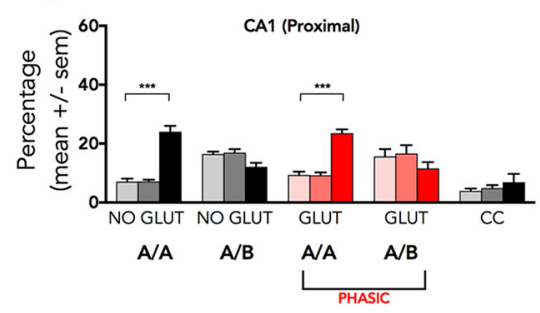

I

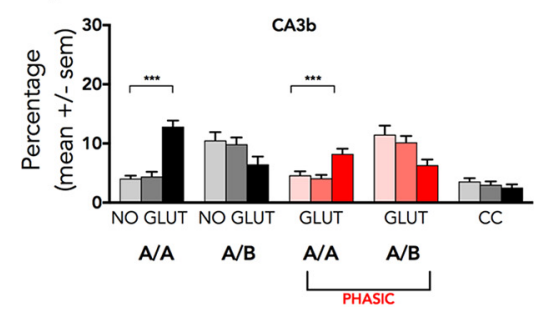

G

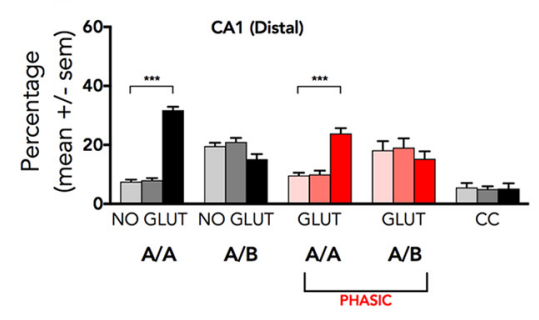

J

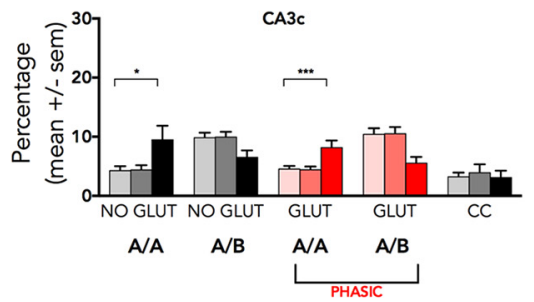

Figure 1. Ipsilateral phasic activation of $L C$ resets a familiar spatial map in DG. A, Timeline and experimental protocol. Environment (box) " $\mathrm{A}$ " with black curtain surround and dim lighting in Room A. Environment (box) " $B$ " with no curtain in bright Room B. B, LC infusion target and example of infusion spread in LC. C, Hippocampal subregions analyzed for mRNA IEG expression. DGS, DG suprapyramidal; CA3a-C, CA1 proximal and distal. D, Categorization of IEG loci for cell counts. N, negative; F, foci; C, cytoplasm; D, doubles; $G$, glia (not counted). $E$, DGS: a greater number of doubles compared with singles observed in the AA NO GLUT group. $\boldsymbol{F}-\boldsymbol{J}$, In all other hippocampal subregions, canonical IEG patterns for familiar and novel spatial maps (NO GLUT A/A and A/B) were maintained; however, ipsilateral LC glutamate (GLUT A/A) did not induce a map reset in these areas. ${ }^{*} p<0.05$, ${ }^{* *} p<0.001$. Red represents phasic activator.

Experimental design. A $63 \mathrm{~cm} \times 63 \mathrm{~cm} \times 35 \mathrm{~cm}$ wooden box with black walls and a white floor divided into nine equal sections was placed on a pedestal in a dimly lit room and was surrounded by black curtains. This comprised the "A" environment. The "B" environment was in a different brightly lit room without curtains. The wooden box was the same size, but the floor was black and there were 8 inch $\times 10$ inch sheets of vertical black-and-white bars on the four walls (Fig. 1). For both A and B environments, rats were placed in the center to begin and then gently moved randomly to another section of the floor every $15 \mathrm{~s}$ to ensure the environment was sampled equally over a 5 min period. After the first open field exposure (Environment A), rats were returned to the colony room for $20 \mathrm{~min}$ and then brought back to Environment A (A/A) or taken to Environment $B(A / B)$ and given the treatment appropriate to their group assignment immediately before their second open field placement in Environment A or B. LC infusions took place just outside the open field over a $30 \mathrm{~s}$ period, and the injectors were left in place for another $60 \mathrm{~s}$ before removal and placement of the animal in its second open field environment. Open field boxes were wiped with $70 \%$ ethanol between rats. Immediately following the second 5 min environmental exposure, rats were briefly anesthetized with isoflurane, decapitated, and brains quickly extracted $(<2 \mathrm{~min})$. Brains were blocked with the brainstem separated from the forebrain. Both pieces were flash frozen in isopentane and placed at $-80^{\circ} \mathrm{C}$ to preserve the integrity of IEG mRNA. Forebrain blocks were packaged in dry ice and shipped to Wilfrid Laurier University for IEG processing. Brainstem blocks were sectioned at Memorial Uni- versity to verify LC localization of drug delivery (Fig. $1 B$ ). Only positive hits are reported. A home cage control (CC) condition $(n=9)$ sacrificed from the home cage was used as a negative control and a maximal electroconvulsive shock condition (Experiment 1, $n=5$; Experiment 2, $n=$ 7; Experiment 3, $n=1$; data not shown, not included in total number of experimental animals), served as a positive control for IEG signaling during in situ hybridization and confocal processing for all experiments, which were run at Wilfrid Laurier University.

For Experiment 1, IEG data were obtained from 6 normal rats for A/A and 6 for A/B as well as 9 CCs that were left undisturbed until death. For unilateral LC glutamate, IEG data were obtained for DG, CA1, and CA3 from 7 brains that received unilateral LC glutamate before A/A, and 5 that received LC glutamate before A/B (Fig. 1A). Total cells counted for each area from rats given open field exposure did not differ across conditions. For Experiment 2, all behavioral conditions were A/A (Fig. 2A); for injector controls, which had infusion cannulae inserted, with or without aCSF infusion, DG, $n=10$; CA1, $n=8$; CA3, $n=7$; for the bilateral glutamate infusions, for all regions $n=6$; for BETH, ORX-A, and CRF infusions, $n=5$ each for DG and $n=3$ each for CA1 and CA3. Experiment 2 included an experimental CC group $(n=5)$ that were moved through nine home cage sections every $15 \mathrm{~s}$ for $5 \mathrm{~min}$ to match the handling protocol of the experimental open field conditions. This was done in the colony room. There were no differences in total cells counted for each region across these conditions. In Experiment 3, animals were tested on both A/A ( $n=5$ for DG and $n=3$ for CA1 and CA3) and A/B 


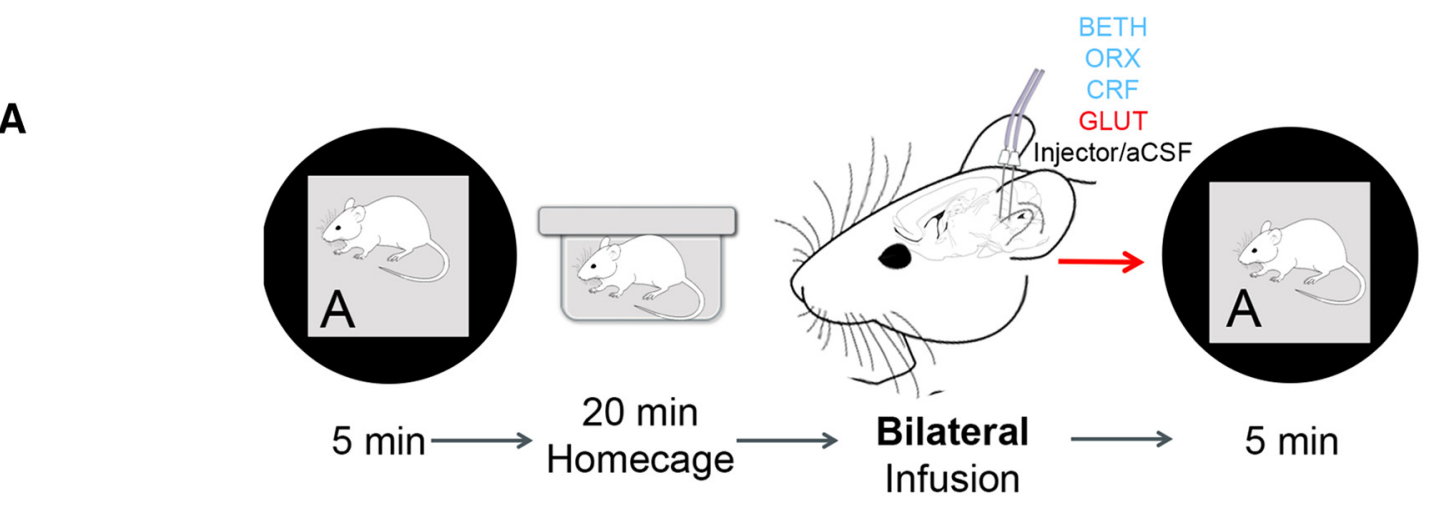

B

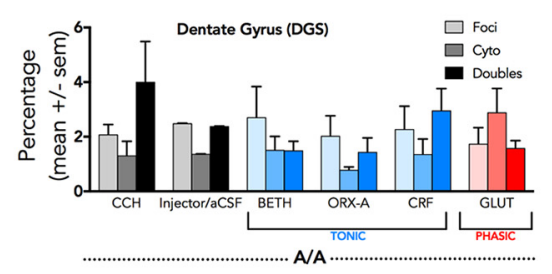

E

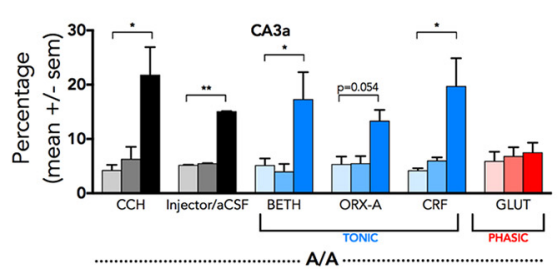

C

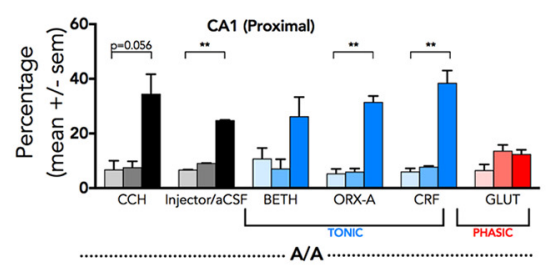

$\mathbf{F}$

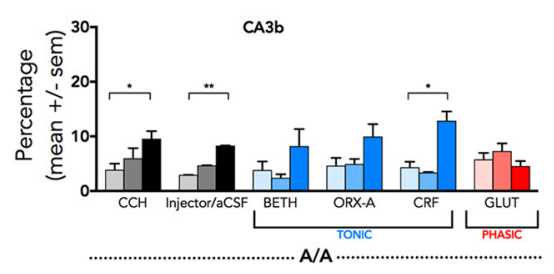

D

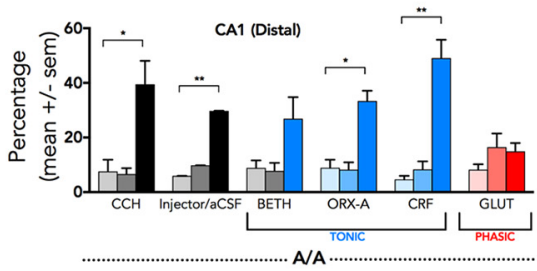

G

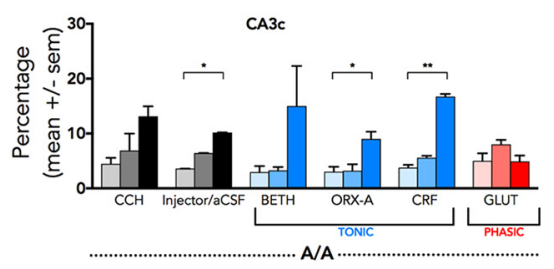

Figure 2. Bilateral phasic, but not tonic, activation of LC resets familiar maps in CA1 and CA3. $A$, Protocol for the bilateral infusion experiment using only the $A / A$ condition. $\boldsymbol{B}$, DGS. There were no significant group differences in IEG loci patterns. This supports the hypothesis that the treatments, all of which generate LC activation, may lead to novel maps being generated in a familiar environment for DGS. C-G, Contrary to the original prediction for the network reset hypothesis with respect to tonic activation, for the pyramidal cells in CA1 and CA3, only bilateral phasic LC activation with glutamate altered the familiar map profile, creating a global reset. All other conditions, including the three tonic activator infusions, were associated with more doubles than singles. These results argue that the DGS remaps with both tonic and phasic increases in LC activity, whereas CA3 and CA1 show a clear distinction between tonic LC increases, with no remapping, and phasic LC-NE increases that reliably evoke global remapping. ${ }^{*} p<0.05,{ }^{* *} p<0.01$, Red represents phasic activator. Blue represents tonic activator.

( $n=7$ for DG, CA1, and CA3) conditions (Fig. 3A). The total cell counts did not differ for DG, but for pyramidal cells, total cell numbers were larger in the $\mathrm{A} / \mathrm{A}$ than $\mathrm{A} / \mathrm{B}$ in $\mathrm{A} / \mathrm{B}$ condition (mean $\pm \mathrm{SEM}$; $\mathrm{A} / \mathrm{A}$ CA1, $91.4 \pm 3.9 ; \mathrm{A} / \mathrm{B} \mathrm{CA} 1,71.2 \pm 2.2 ; \mathrm{CA} 3 \mathrm{~A} / \mathrm{A}, 77.4 \pm 3.65 ; \mathrm{A} / \mathrm{B}, 64.7 \pm 1.54)$. These differences do not alter the interpretation of results.

FISH. FISH was performed as previously described (Guzowski et al., 1999). Briefly, full-length Arc riboprobes were synthesized using a commercial transcription kit (MaxiScript; Ambion) and RNA labeling mixes (Roche Diagnostics), verified by electrophoresis. Slides were thawed to $-20^{\circ} \mathrm{C}$ overnight and then to room temperature $1 \mathrm{~h}$ before processing. They were fixed in $4 \%$ formaldehyde $(5 \mathrm{~min})$, washed in $2 \times$ salinesodium citrate (SSC) ( $2 \mathrm{~min}$ ), and treated with $0.5 \%$ acetic anhydride (10 $\mathrm{min})$. Next, they were dipped in deionized water, placed in a methanol/ acetone (1:1) solution ( $5 \mathrm{~min}$ ), and in $2 \times$ SSC ( $5 \mathrm{~min})$. Slides were then incubated with prehybridization buffer (Sigma-Aldrich) for $1 \mathrm{~h}$ at room temperature and then overnight $(16-18 \mathrm{~h})$ at $56^{\circ} \mathrm{C}$ with riboprobe mixed in hybridization buffer ( $100 \mathrm{ng}$ per slide). The following day, the tissue was treated with a series of $2 \times$ SSC washes and then in an RNA-ase A/2 $\times$ SSC solution $(10 \mathrm{mg} / \mathrm{ml})$ at $37^{\circ} \mathrm{C}$ for $30 \mathrm{~min}$. This was followed by a series of $0.5 \times \mathrm{SSC}$ washes, including $30 \mathrm{~min}$ at $55^{\circ} \mathrm{C}$. Endogenous peroxidases were then quenched with a $2 \% \mathrm{H}_{2} \mathrm{O}_{2}$ (in $1 \times$ SSC) solution. The tissue was blocked with TSA blocking buffer (PerkinElmer) containing normal sheep serum $(0.5 \%)$, and incubated with anti-digoxigenin-HRP antibody (Roche Diagnostics) in TSA blocking buffer (1:400) for $2 \mathrm{~h}$ at room temperature. Slides were washed in $0.1 \mathrm{M}$ Tris-buffered saline with $0.05 \%$ Tween 20, and HRP antibody conjugates were detected using CY3 (TSA kit, PerkinElmer, catalog \#NEL704A001KT, RRID:AB_2572409). The fi- nal step involved counterstaining the nuclei with DAPI (Sigma-Aldrich), sealing with buffered glycerol (with antifade) and coverslipping. Slides were then placed in the fridge for storage.

Image acquisition and analysis. Images were collected from coronal sections of the HPC (range: anteroposterior -2.5 to -4.2 ) relative to bregma (Paxinos and Watson, 2013), including the suprapyramidal blade of the DG, the CA1 medial (CA1 distal) and lateral (CA1 proximal) regions, and the $\mathrm{CA} 3 \mathrm{a}, \mathrm{CA} 3 \mathrm{~b}$, and $\mathrm{CA} 3 \mathrm{c}$ subregions (Fig. $1 C$ ), using an Olympus FV1000 confocal microscope at $40 \times$ magnification. We decided not to look in detail at the infrapyramidal blade of the DG because in Experiment 1 we only found environmentally specific IEG expression in the suprapyramidal blade as reported by others (e.g., Chawla et al., 2005; Marrone et al., 2014; Gheidi et al., 2013). For Experiment 1, for each animal, two $z$ stacks $(\sim 1.0 \mu \mathrm{m}$ optical thickness, step size $0.8 \mu \mathrm{m})$ were collected from 2 or 3 different slides yielding $4-6$ total stacks per region, and images were collected only from the left hemisphere. For Experiments 2 and 3, one $z$ stack $(\sim 1.0 \mu$ m optical thickness, step size 0.8 $\mu \mathrm{m}$ ) was collected from each hemisphere on 2 or 3 different slides yielding 4-6 total stacks per region. Data from each hemisphere were then pooled. For the DG, images on the first slide were taken from the region closest to the geniculate; on the second slide, images were taken from the region farthest from the geniculate; and on the third slide, images were taken in the middle ensuring that the entire DG was sampled. For each slide, acquisition parameters were kept constant. The median $20 \%$ of neurons in each stack was quantified using MetaMorph software (MetaMorph Microscopy Automation and Image Analysis Software, RRID: SCR_002368). Neurons and glial cells were differentiated by size and 
A

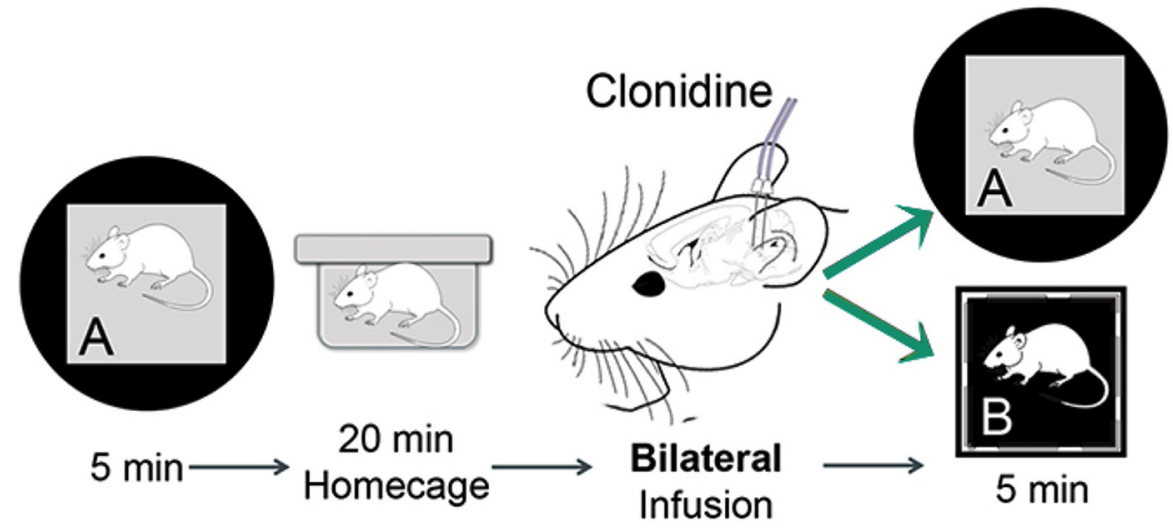

B

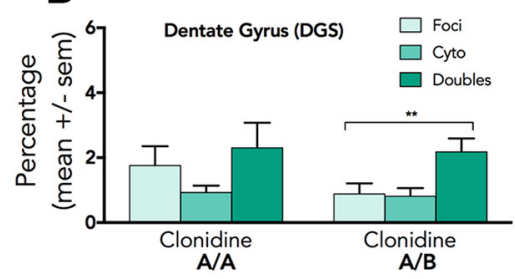

$\mathbf{E}$

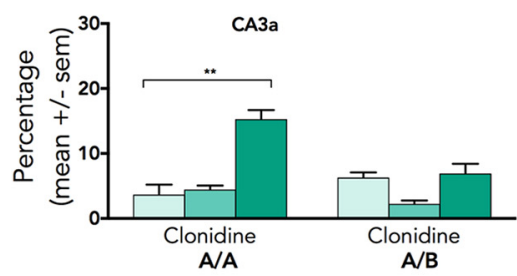

C

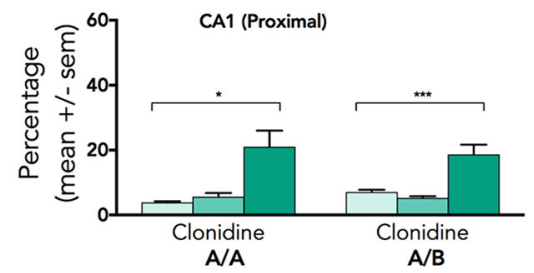

$\mathbf{F}$

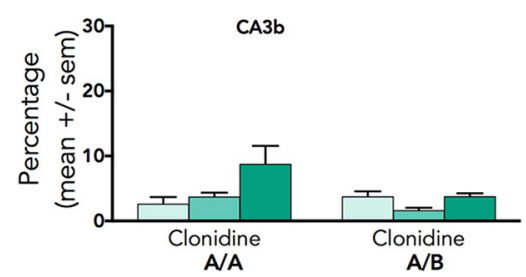

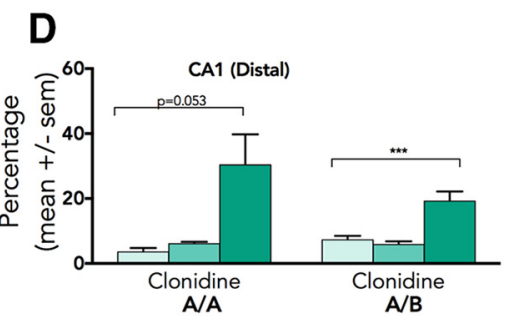

G

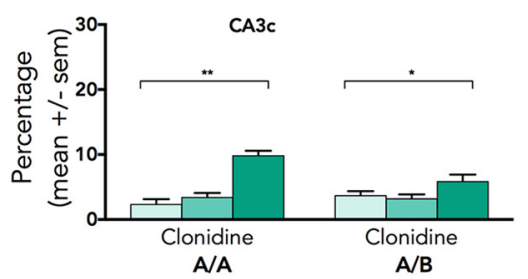

Figure 3. LC inactivation results in familiar map generation in a novel environment for DGS and CA1. $A$, Protocol for LC inactivation using bilateral clonidine. $\boldsymbol{B}-\mathbf{G}$, We predicted similar profiles for $A / A$ and $A / B$ conditions resulting from $L C$ inactivation prevention of novelty encoding, which we found for DGS and CA1, and CA3C, but not for $C A 3$ a and $C A 3 b$. Silencing the $L C$ in the $A / A$ condition would not be expected to alter the already formed A representation because the LC is not normally activated in familiar environments. The familiar " $A$ " map in the $A / A$ condition was demonstrated in CA3 and CA1. In the DGS condition, there were increased doubles, but also increased IEG foci. We found that LC silencing effects differed depending on the hippocampal subregion. The familiar " $A$ " map was reactivated in DGS and CA1 in the novel environment, but not in CA3a or CA3b, where the representations reflected a novel map. This argues that internal state (LC activation) is required for the generation of a new map in the presence of changed external input in DGS and CA1, but not in CA3a or CA3b. ${ }^{*} p<0.05,{ }^{* *} p<0.01,{ }^{* * *} p<0.001$. Green represents LC inhibitor.

patterns of chromatin staining, and neurons in the CA1 and CA3 were classified as Arc-negative (neg), Arc-positive within the nucleus (foci), or Arc-positive within the cytoplasm (cyto). Cells with IEG expression in any of these compartments is considered a single-labeled cell, and compared with those that are Arc-positive within both the nucleus and the cytoplasm (double) (Fig. 1D). For the DG, Zif268 was quantified instead of Arc because Arc undergoes sustained transcription in the DG following context exposure (Ramirez-Amaya et al., 2013; Maple et al., 2017). Within each animal, an average of $1143 \pm 74.66$ granule cells were counted in the DG, $454.93 \pm 44.25,429.41 \pm 59.37$, and $488.62 \pm 63.77$ pyramidal cells were counted in the CA3a-c, respectively, and $543.95 \pm$ 37.67 and $530.86 \pm 38.99$ pyramidal cells were counted in the CA1 proximal and distal regions respectively. Cells Arc- or Zif268-positive in the cytoplasm were engaged in transcription $30 \mathrm{~min}$ before decapitation, whereas cells Arc- or Zif268-positive in the nucleus were engaged in transcription $5 \mathrm{~min}$ before. Doubles were engaged in transcription at both time points.

Statistical analyses. Calculated statistics are presented as mean \pm SEM. To analyze differences, we used repeated-measures two-way ANOVAs [Group (between-subject factor) $\times$ IEG loci (within-subject factor)]. Follow-up comparisons (one-way ANOVAs) and post hoc analyses (Tukey's HSD) captured differences in the patterns of IEG loci. Comparisons between the percentage of doubles against chance were also done using two-way repeated-measures ANOVAs [Group (between-subject factor) $\times$ Doubles vs Chance (within-subject factor)], and finally total IEG counts were conducted the same way [Group (between-subject fac- tor) $\times$ Epoch 1 vs Epoch 2 (within-subject factor)]. Each sample is based on data from 1 rat.

\section{Results}

Ipsilateral phasic activation of LC resets a familiar spatial map in DG

As mentioned, forebrains were only analyzed for positive infusions, defined as methylene blue dye in LC or its dendritic region. The actual spread of the $0.2 \mu \mathrm{l}$ bolus infusions was estimated in a subset of 10 rats (medial lateral spread $=642 \pm 72.7 \mu \mathrm{m}$; anterior-posterior spread $=690 \pm 86.2 \mu \mathrm{m}$ ). Track damage and the adjacent fourth ventricle precluded accurate dorsal-ventral estimates. An illustrative example of methylene blue spread is seen in Figure $1 B$.

In DGS, unilateral LC glutamate reset of the ipsilateral IEG map in the A/A condition was evidenced by absence of a familiar map profile, significantly more doubles (cyto and foci positive neurons) than singles (cyto only or foci only positive neurons) (Fig. $1 E$ ). In $\mathrm{A} / \mathrm{A}$ and $\mathrm{A} / \mathrm{B}$ controls, we replicated the canonical IEG pattern of a familiar map with more doubles than singles for the A/A condition (Guzowski et al., 1999; Skinner et al., 2014; Carasatorre et al., 2015) (Fig. 1E). Overall, there was a main effect of IEG loci with more doubles than singles observed (and a significant interaction, $F_{(8,56)}=5.362, p=0.00005$; two-way 
repeated-measures ANOVA). As expected, a greater number of doubles compared with singles were seen in the A/A group (NO GLUT) where animals visited the same context twice $\left(F_{(2,10)}=\right.$ 25.07, $p=0.000127$; one-way ANOVA). Animals in the A/A condition that were given ipsilateral glutamate LC did not show this pattern in DGS $\left(F_{(2,18)}=1.343, p=0.286\right.$; one-way ANOVA). Therefore, ipsilateral LC glutamate activation was able to reset the DGS map in a familiar environment.

When animals traverse two unfamiliar or novel environments, doubles are typically similar to, or significantly less than, the number of singles as seen for A/B (NO GLUT) animals (Fig. $1 E)$. LC activation would normally occur in a novel environment; thus, no effect of ipsilateral LC glutamate was predicted in the $\mathrm{A} / \mathrm{B}$ condition, and no differences were observed (Fig. $1 E$ ). In all other hippocampal subregions, canonical IEG patterns for familiar and novel spatial maps (NO GLUT A/A and A/B) were maintained; however, ipsilateral LC glutamate (GLUT A/A) did not induce a map reset in these areas (Fig. $1 F-J$ ). For CA3a-c, there was a significant Group $\times$ IEG Loci interaction $\left(\mathrm{CA} 3 \mathrm{a}: F_{(8,56)}=\right.$ $11.445, p=1.89147698 \mathrm{e}-9$; CA3b: $F_{(8,56)}=31.571, p=$ $2.4721603 \mathrm{e}-10$; CA3c: $F_{(8,56)}=8.24, p=0.000$; two-way repeated-measures ANOVA). Follow-up comparisons showed more doubles than singles in the NO GLUT A/A group (CA3a: $F_{(2,10)}=49.47, p=0.00000652$; CA3b: $F_{(2,10)}=64.0, p=$ 0.0000020 ; CA3c: $F_{(2,10)}=5.85, p=0.021$; one-way ANOVAs), and in the LC GLUT A/A group (CA3a: $F_{(2,12)}=11.06, p=0.002$; CA3b: $F_{(2,12)}=23.79, p=0.00006676$; CA3c: $F_{(2,12)}=19.92, p=$ 0.00015385; one-way ANOVAs), both indexing a familiar environment. Thus, ipsilateral LC glutamate does not reset CA3 maps, although doubles were lower for the LC GLUT A/A condition than the NO GLUT A/A condition across the 3 subregions.

In $\mathrm{CA} 1$, there was also no evidence of global reset with ipsilateral LC activation. Similarly, there was a significant Group $\times$ IEG Loci interaction in proximal CA1 $\left(F_{(8,56)}=18.95, p=2.11 \mathrm{e}^{-13}\right)$ and in distal CA1 $\left(F_{(8,56)}=43.16, p<2.11 \mathrm{e}^{-13}\right)$. Follow-up comparisons showed a higher proportion of doubles compared with singles in the NO GLUT A/A (proximal CA1: $F_{(2,10)}=98.50$, $p=0.00000026$; distal CA1: $F_{(2,10)}=412.21, p=2.4721603 \mathrm{e}^{-10}$; one-way ANOVAs) and LC GLUT A/A groups (proximal CA1: $F_{(2,12)}=148.72, p=3.40117301 \mathrm{e}^{-9}$; distal CA1: $F_{(2,12)}=61.25$, $p=0.00000050$; one-way ANOVAs).

\section{Bilateral phasic, but not tonic, activation of LC resets familiar maps in CA1 and CA3}

Contrary to the original prediction for the network reset hypothesis with respect to tonic activation (Bouret and Sara, 2005), for the pyramidal cells in CA1 and CA3, only bilateral phasic LC activation with glutamate altered the familiar map profile, creating a global reset. All other conditions, including the three tonic activator infusions, were associated with more doubles than singles (Fig. $2 C-G$ ). For proximal CA1, each of the tonic activators was associated with familiar map profiles, whereas in distal CA1, the BETH profile was marginal while the other two tonic activators produced clear familiar profiles (Fig. $2 C, D$ ). In both CA 3 and CA1, bilateral glutamatergic phasic LC activation was associated with a map reset.

Significant Group $\times$ IEG Loci interactions were revealed in the CA3 (CA3a, $F_{(10,42)}=2.326, p=0.028$; CA3b, $F_{(10,44)}=3.62$, $p=0.002$; CA3c, $\left.F_{(10,44)}=2.75, p=0.01\right)$. In CA3a (Fig. $\left.2 E\right)$, all groups, except for the phasic GLUT LC group, showed more doubles than singles shown by separate one-way ANOVAs (CC Handled $[\mathrm{CCH}]: F_{(2,8)}=7.53 p=0.014$; LC Injector/aCSF: $F_{(2,12)}=$ $13.80, p=0.001$; BETH: $F_{(2,4)}=8.526 p=0.036$; ORX-A: $F_{(2,4)}=$
6.625, $p=0.054$; CRF: $\left.F_{(2,4)}=8.386, p=0.037\right)$. The phasic GLUT LC group demonstrated a novel map. In CA3b (Fig. $2 F$ ), patterns were similar to those observed in CA3a, although significantly more doubles were only seen in the $\mathrm{CCH}$, Injector/aCSF, and CRF groups (CCH: $F_{(2,8)}=3.364 p=0.075$; Injector/aCSF: $F_{(2,14)}=14.65 p=0.001$; BETH: $F_{(2,4)}=3.688 p=0.124$; ORX-A: $F_{(2,4)}=3.336 p=0.14$; CRF: $\left.F_{(2,4)}=26.185 p=0.005\right)$. The phasic GLUT LC group again showed a novel pattern. In CA3c (Fig. 2G), the Injector/aCSF, ORX-A, and CRF groups exhibited familiar profiles (CCH: $F_{(2,8)}=3.697, p=0.073$; Injector/ aCSF: $F_{(2,14)}=6.378, p=0.011$; BETH: $F_{(2,4)}=3.226, p=0.146$; ORX-A: $F_{(2,4)}=7.995, p=0.04$; CRF: $\left.F_{(2,4)}=216.2, p=0.001\right)$. The phasic LC GLUT group showed a novel pattern.

There were significant Group $\times$ IEG Loci interactions in both proximal $\left(F_{(10,44)}=2.59, p=0.015\right.$; two-way repeated-measures ANOVA $)$ and distal CA1 $\left(F_{(10,44)}=2.60, p=0.014\right.$; two-way repeated-measures ANOVA) (Fig. 2C,D). Following separate one-way ANOVAs, familiar patterns were observed in $\mathrm{CCH}$ $\left(F_{(2,6)}=4.83, p=0.056\right)$, Injector/aCSF $\left(F_{(2,14)}=7.59, p=0.006\right)$, $\operatorname{ORX}-\mathrm{A}\left(F_{(2,4)}=313.4, p=0.00004021\right)$, and $\operatorname{CRF}\left(F_{(2,4)}=45.99\right.$, $p=0.002)$ in proximal CA1. This was not observed in BETH $\left(F_{(2,4)}=5.19, p=0.08\right.$. However, the expression pattern for phasic LC GLUT was similar to what is observed when an animal explores a novel environment (Fig. 2C). In distal CA1, separate one-way ANOVAs revealed significantly more doubles than singles were observed in $\mathrm{CCH}\left(F_{(2,8)}=7.92, p=0.013\right)$, Injector/ $\operatorname{aCSF}\left(F_{(2,14)}=11.45, p=0.001\right)$, ORX-A $\left(F_{(2,4)}=14.78, p=\right.$ $0.014)$, and $\operatorname{CRF}\left(F_{(2,4)}=30.04, p=0.004\right)$. Again, this was not observed in BETH $\left(F_{(2,4)}=4.85, p=0.085\right)$. Phasic LC GLUT animals demonstrated a novel IEG pattern (Fig. $2 D$ ). While animals in the BETH group showed the most variability of tonic activators in these small samples, for the CA3 and CA1 subregions together, there was a main effect of IEG loci with higher doubles compared with singles in the BETH group $\left[F_{(2,16)}=7.82, p=0.04\right.$; two-way (IEG Loci $\times$ HPC subregion) repeated-measures ANOVA].

In the DGS, none of the pharmacological LC conditions was associated with a familiar map profile, including the Injector/ aCSF condition (Fig. 2B). Therefore, the DGS remapped with both tonic and phasic increases in LC activity.

The home $\mathrm{CC}$ rats $(\mathrm{CCH})$ in Experiment 2 were run with the same protocol as the experimental rats, but in home cages in the colony room. This handling protocol increased the number of IEG-positive cells in $\mathrm{CCH}$ rats compared with undisturbed CCs (CC) in Experiment 1 (Fig. 1 vs Fig. 2). This conclusion is supported by significantly higher total IEG expression within each hippocampal subregion in Experiment 2 versus Experiment 1 (CA1 distal: $F_{(1,12)}=39.48, p=0.00004$; CA1 proximal: $F_{(1,12)}=6.427, p=$ 0.026; CA3a: $F_{(1,12)}=19.77, p=0.001$; CA3b: $F_{(1,12)}=5.405$, $p=0.038$; CA3c: $F_{(1,12)}=12.043, p=0.005$; DGS: $F_{(1,17)}=13.924$, $p=0.002$; two-way repeated-measures ANOVA) (also Fig. 4 ). The primary effect of handling in the $\mathrm{CCH}$ group was to increase the number of doubles. This effect is supported by a significant Group $\times$ IEG Loci interaction (CA1 distal: $F_{(2,24)}=14.304, p=$ 0001; CA1 proximal: $F_{(2,24)}=5.538, p=011$; CA3a: $F_{(2,24)}=$ $12.046, p=0.002$; CA3b: $F_{(2,24)}=17.513, p=0.007$; CA3c: $F_{(2,24)}=5.374, p=0.013 ;$ DGS: $F_{(2,24)}=4.28, p=0.051$; two-way repeated-measures ANOVA).

The handled home cage maps corresponded to familiar maps for all pyramidal cell subregions but are only marginally significant for DGS granule cells. Thus, in Long-Evans rats undergoing the experimental handling protocol in the home cage, there is not clear evidence for the presence of a familiar map in DGS. This possible reset 
A

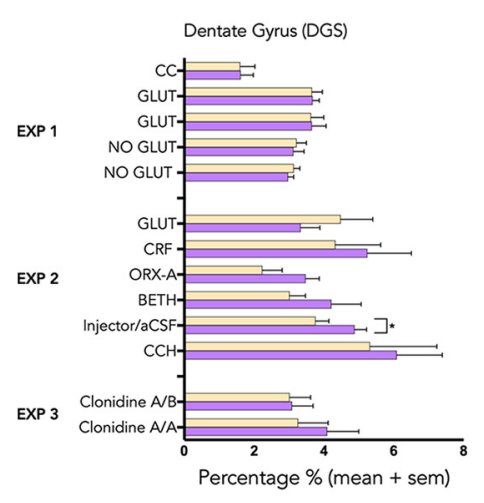

D

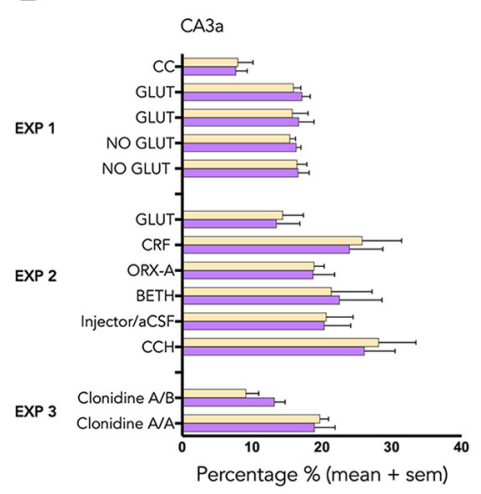

B

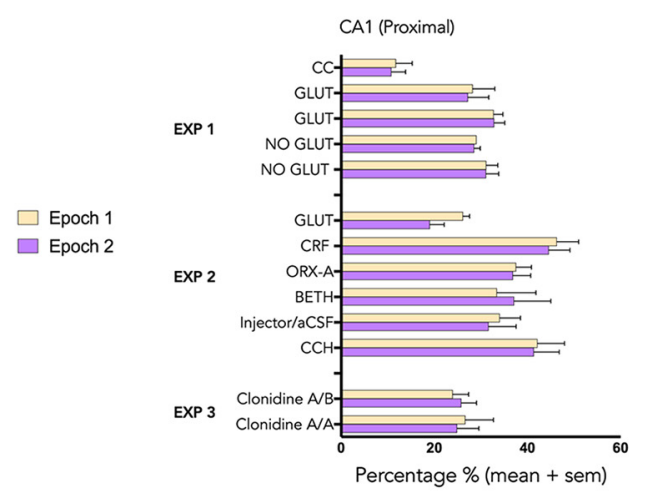

E

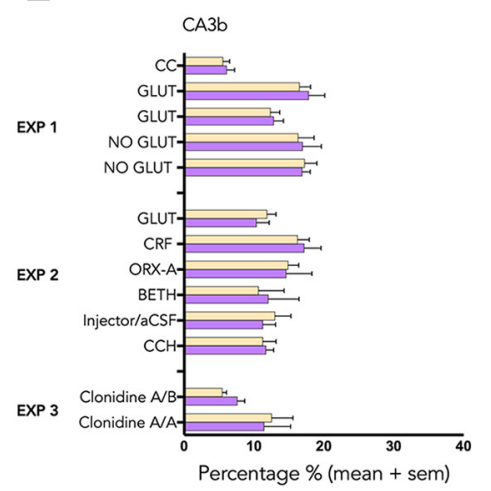

C

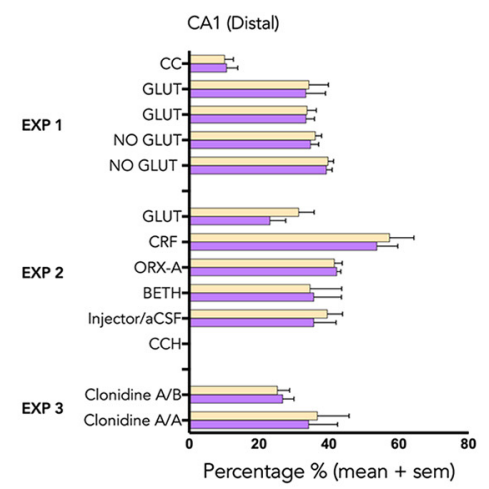

$\mathbf{F}$

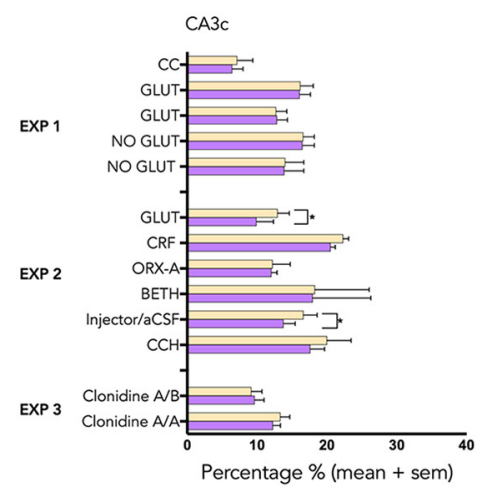

Figure 4. Total IEG expression remains constant across both behavioral epochs. ${ }^{*} p<0.05$. Yellow represents the first behavioral epoch (Environment A). Purple represents the second behavioral epoch (Environment A or B). $\boldsymbol{A}-\boldsymbol{F}$, The percentage of total IEG expression is shown across all three experiments across each of the six hippocampal regions. $\boldsymbol{B}-\boldsymbol{E}$, IEG expression remains constant across epochs in each region except in the (A) DGS and (F) CA3C.

effect in DGS may again relate to its sensitivity to LC activation as seen in Experiment 1, but remains to be confirmed.

\section{LC inactivation results in familiar map recall in a novel environment for both DGS and CA1}

In Experiment 3, we used the $\alpha$ - 2 adrenergic agonist, clonidine, before placement in Environment B, to silence the LC (Berridge et al., 1993). While clonidine is somewhat more lipophilic (Timmermans et al., 1977) than the activators used in Experiments 1 and 2, bolus infusions have produced highly localized LC effects in previous studies (De Sarro et al., 1987; Sakamoto et al., 2013; Clément et al., 2014; Cummins Jacklin et al., 2015). We predicted similar profiles for $\mathrm{A} / \mathrm{A}$ and $\mathrm{A} / \mathrm{B}$ conditions resulting from $\mathrm{LC}$ inactivation preventing novelty environment encoding. We found that LC input was required for novel map generation in DGS, CA3c, and CA1, but not in CA3a and CA3b (Fig. 3). Rats given clonidine before placement in the "B" environment produced the familiar "A" environment map in DGS [main effect of IEG Loci, $F_{(2,18)}=6.55, p=0.007$, two-way repeated-measures ANOVA) (Fig. 3B), CA3c (Group $\times$ IEG Loci interaction, $F_{(2,16)}=$ $7.73 p=0.004$, two-way repeated-measures ANOVA) (Fig. $3 G$ ) and CA1 (proximal: main effect of IEG Loci, $F_{(2,16)}=30.59, p=$ 0.00000341; distal: main effect of IEG Loci, $F_{(2,16)}=26.55, p=$ 0.00000826; two-way repeated-measures ANOVA) (Fig. $3 C, D)$. Follow-up comparisons showed significantly more doubles than singles in the A/B group in the DGS $\left(F_{(2,10)}=10.38, p=0.004\right.$, one-way ANOVA) (Fig. $3 B)$, the CA3c $\left(F_{(2,12)}=5.61, p=0.019\right.$, one-way ANOVA) (Fig. $3 G$ ), and the CA1 (proximal: $F_{(2,12)}=$
$21.3, p=0.0001127$; distal: $F_{(2,12)}=20.45, p=0.0001362$; oneway ANOVA) (Fig. 3C,D).

In contrast, a globally remapped representation was evident in CA3a (Group $\times$ IEG Loci interaction, $F_{(2,16)}=10.15, p=0.001$, two-way repeated-measures ANOVA; Fig. $3 E$ ), and CA3b (Group $\times$ IEG Loci interaction, $F_{(2,16)}=6.28, p=0.01$, two-way repeated-measures ANOVA interaction; Fig. $3 F$ ). In each case, the Clonidine $\mathrm{A} / \mathrm{A}$ and Clonidine $\mathrm{A} / \mathrm{B}$ groups differed in pattern, with the A/A group having a familiar pattern $\left(\mathrm{CA} 3 \mathrm{a}: F_{(2,4)}=\right.$ 37.85, $p=0.003$; CA3b: $\left.F_{(2,4)}=5.49, p=0.071\right)$ and the A/B group showing no differences across the intracellular profile of Arc expression. CA3c is located within the boundaries of the DG and may reflect more DG-like processing characteristics (Hunsaker and Kesner, 2008; Marrone et al., 2014). Supporting this idea, Hunsaker et al. (2008) found the most severe deficits in spatial processing in rats were observed when the animals sustained lesions to the DG and to the CA3c subregions of the HPC. They were impaired in novelty detection whether changes to the environment were great or small. In contrast, lesions to the CA3a and CA3b did not produce such impairment.

Silencing the LC in the A/A condition would not be expected to alter the already formed " $\mathrm{A}$ " representation because the $\mathrm{LC}$ is not normally activated in familiar environments. The familiar "A" map in the A/A condition was demonstrated in CA 3 and CA1 (Fig. $3 C-G$ ). In the DGS condition, there were increased doubles, but also increased IEG foci (Fig. 3B), as seen in Experiment 2 (Fig. $2 B$ ) after LC activation. The intermediate pattern in DGS also occurred for A/A with LC CRF activation in Experiment 2. 
A

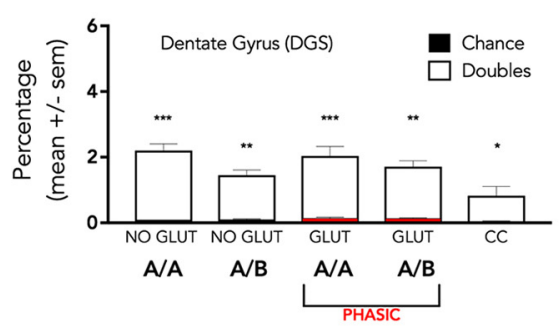

D

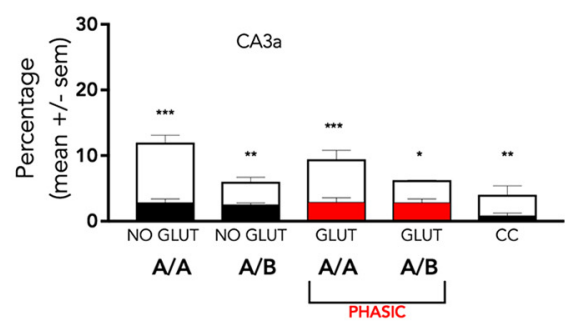

B

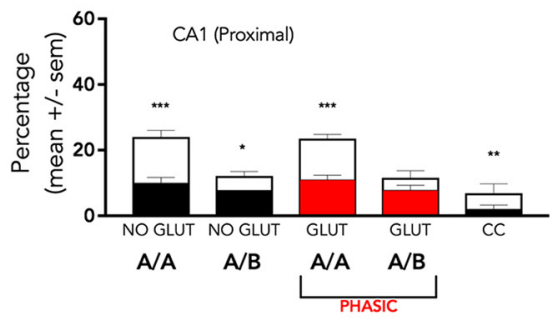

E

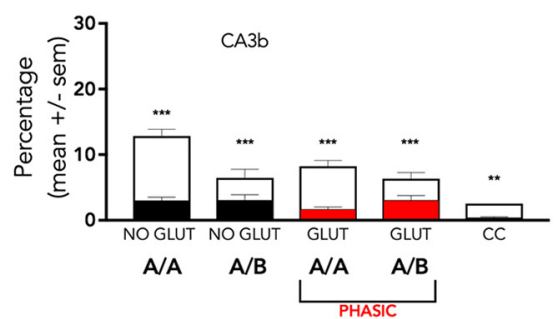

C

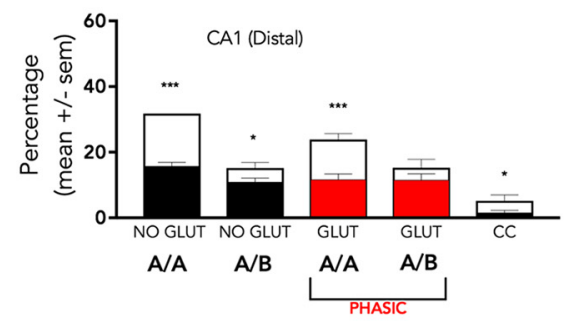

F

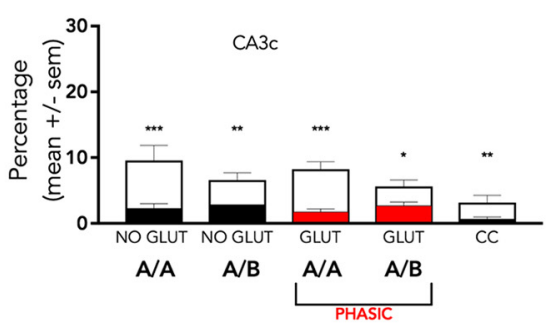

Figure 5. The percentage of neurons labeled as doubles in Experiment 1 for each HPC subregion is greater than chance. ${ }^{*} p<0.05,{ }^{* *} p<0.01$, ${ }^{* * *} p<0.001$. All groups demonstrated a percentage of doubles above chance apart from the GLUT AB group in the CA1. Unfilled bars represent doubles. Filled bars represent chance values. Red represents phasic activator. A/A: animals visited the same context twice (familiar) A/B: animals visited two different contexts (novel) GLUT: ipsilateral glutamate infusion CC: caged controls.

A

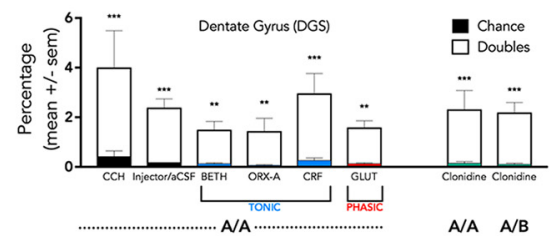

D

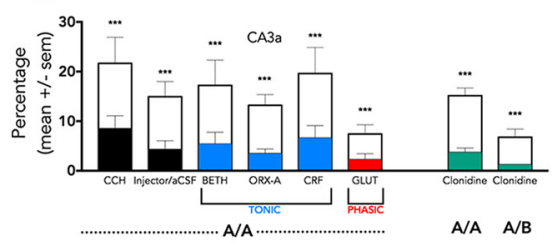

B

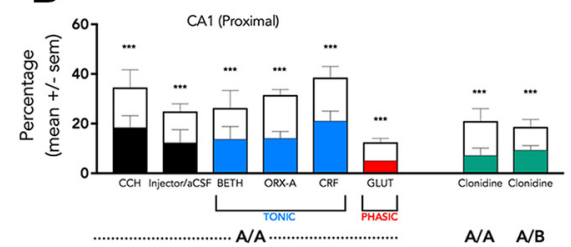

E

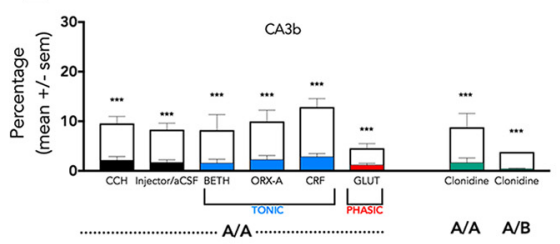

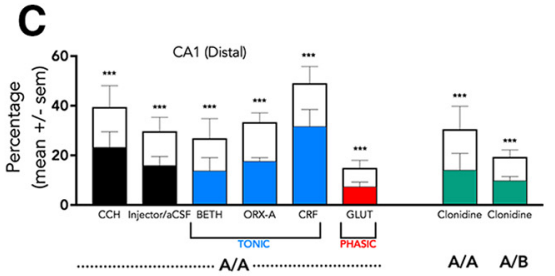

F

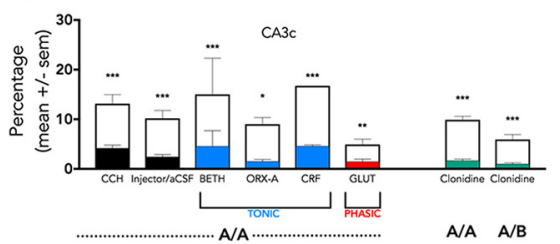

Figure 6. The percentage of neurons labeled as doubles in Experiments 2 and 3 for each HPC subregion is greater than chance. ${ }^{*} p<0.05,{ }^{* *} p<0.01$, ${ }^{* * *} p<0.001$. All groups demonstrated a percentage of doubles above chance. Red represents phasic activator. Blue represents tonic activator. Green represents $\mathrm{LC}$ inhibitor. Unfilled bars represent percentage of doubles. Filled bars

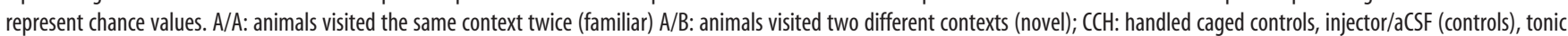
activators (BETH, ORX-A, CRF) bilateral infusions of bethanechol, orexin A, or corticotropin-releasing factor, phasic activator (GLUT) bilateral glutamate infusions, Clonidine: bilateral infusions of clonidine.

For all groups except the DGS (main effect of Epoch, $F_{(1,68)}=$ $4.60, p=0.0036$, two-way repeated-measures ANOVA) and the CA3c (main effect of Epoch, $F_{(1,68)}=4.105, p=0.0047$, two-way repeated-measures ANOVA), total IEG expression was constant across environment exposures (Fig. 4A-F). Comparisons between the percentage of doubles in all conditions across all brain regions against chance values are also reported for Experiment 1 (Fig. 5A-F) and Experiments 2 and 3 (Fig. 6A-F). In every case, the percentage of doubles was well above chance (interactions, DGS: $F_{(1,68)}=4.105, p=0.0047$; CA1 proximal: $F_{(12,58)}=4.53$, $p=0.00$; CA1 distal: $F_{(12,58)}=5.406, p=0.00 ;$ CA3a: $F_{(12,57)}=$ $7.376, p=0.00$; CA3b: $F_{(12,58)}=8.585, p=0.00$; CA3c: $F_{(12,58)}=$ $5.518, p=0.00$; two-way repeated-measures ANOVA). Interestingly, however, in the CA1, both proximally and distally, even though the $\mathrm{A} / \mathrm{B}$ group showed a percentage of doubles greater than chance, phasic LC glutamate induced a reset ip- silaterally such that this was no longer the case (GLUT AB; Fig. $5 B, C)$.

\section{Discussion}

We found that ipsilateral LC glutamate activation was able to reset the DGS map in a familiar environment and phasic bilateral LC activation globally remapped representations in DG, CA3, and CA1 in a familiar environment. This dramatic result supports the network reset hypothesis (Bouret and Sara, 2005) and reveals a nonspatial determinant of hippocampal representations thought to form the underpinnings of episodic memory, consonant with the view that representations are constantly updated in the face of new information (McKenzie and Eichenbaum, 2011).

Remapping in a familiar environment is consistent with proposals that hippocampal representations may be viewed as abstract networks which incorporate spatial, temporal, sensory, and 
motivational information by indexing distributed cortical events representing an experience (Teyler and DiScenna, 1986; Teyler and Rudy, 2007). The view of hippocampal representations as traces of episodic memories, serving to protect other memories from interference, has extensive support (McKenzie and Eichenbaum, 2011; Tonegawa et al., 2015; Bulkin et al., 2016). The HPC uses a sparse coding scheme to separate experiences, even when they may be highly similar, or when they occur in familiar settings, situations in which the contextual cues then require the acquisition of new meanings. Our observation that a salient LC signal recruits a new network representation in an unchanged environment is in accordance with these concepts and provides one mechanism by which this may occur. The importance of the LC episodic memory signal is underlined by a failure to encode new space as a new map in DGS, CA1, and CA3c when LC is silenced.

Regional differences in the impact of LC silencing on hippocampal representations are highlighted in a recent optogenetic study (Wagatsuma et al., 2018). However, those effects concerned map stabilization, not map initiation. Silencing the LC after encoding prevented stabilization, and local LC fiber inactivation in the HPC showed stabilization depended on CA3 only. Our data show that CA3a/b responds differently to the tension between changed external input and absence of the LC signal relative to DG, CA1, and CA3c. DG, CA1, and CA3c retrieve the old map in the new context, consistent with its prior stabilization, while CA3a/b generates a new map. Trisynaptic circuitry connectivity per se (DG/CA3/CA1) does not drive hippocampal representations consistent with other studies (e.g., Karlsson and Frank, 2008). CA3a/b is more sensitive to environmental input as a trigger for global remapping than are CA3c, DG, and CA1. CA3a/b global remapping may be supported by non-LC neuromodulatory novelty signals, insufficient to trigger changes in DG, CA1, and $\mathrm{CA} 3 \mathrm{c}$.

Consistent with our findings that LC bursts can induce global map reset in an unchanged environment, is evidence by Moita et al. (2004) that brief foot shock in a familiar environment initiates global CA1 map reset. Foot shock phasically activates the LC (Chen and Sara, 2007).

Distinct LC tonic and phasic activation effects have been seen in optogenetic experiments. Tonic LC optogenetic activation is associated with stress, producing anxiety and aversion as a function of frequency. Anxiogenic effects also occur with activation of LC-CRF receptors. Phasic LC activation, paralleling LC responses to novel and salient stimuli, is not stress-inducing, even with frequency increases (McCall et al., 2015). Phasic, not tonic, LC activation generates enhanced sensory salience in cortex, recruiting unresponsive cells and generating the P300 wave (Vazey et al., 2018), a metric of cognitive function.

Phasic activation of LC induces changes in network dynamics proposed to promote adaptive behavior at critical times when learning is necessary (Sara et al., 1994; Bouret and Sara, 2005; Hagena et al., 2016). We show this occurs within the HPC with the generation of a new episodic map, and suggest that the LC system biases the memory system toward episodic encoding when new or salient information is available. One example of this is reversal learning, which is associated with phasic $\mathrm{LC}$ activation (Aston-Jones et al., 1994, 1997; Rajkowski et al., 1994; AstonJones and Cohen, 2005). The way in which the switch between memory encoding and retrieval separates memories and promotes adaptive behavior is poorly understood. This is a concern because dysregulation in memory updating may underlie anxiety disorders, such as post-traumatic stress disorder (Maren et al.,
2013; Morrison and Ressler, 2014; Liberzon and Abelson, 2016; Sheynin and Liberzon, 2017).

The present experiments only index global remapping. Rate remapping, place field rotation, or place field splitting occurring with novelty would not be detected as a loss of network overlap, unless lower firing rates failed to trigger IEG transcription. Tonic LC input may support rate remapping. This remains to be studied.

The optogenetic experiments, together with the present findings, suggest patterns and timing of LC firing is critical for outcomes. Two features may mediate pattern differences. First is the strength and nature of LC-released neurotransmitters. NE interacts with receptors that have different thresholds for recruitment (see Salgado et al., 2012). Higher release per impulse occurs with bursts and will alter concentrations (Florin-Lechner et al., 1996). Bursts also facilitate peptide cotransmitter release (Lundberg et al., 1989; Wilcox and Unnerstall (1990); Trudeau, 2004; VilaPorcile et al., 2009; Kourtesis et al., 2015). LC axons can release dopamine (Smith and Greene 2012; Takeuchi et al., 2016; Kempadoo et al., 2016), an effect that may link to firing patterns. Differential postsynaptic receptor activations would mediate different outcomes. Second, the pause in LC firing is a canonical difference between burst and tonic firing. How might this pause contribute to alter LC's modulatory effect? Noradrenergic receptor actions are modified by changes in G-proteins (e.g., Chay et al., 2016). If these effects are sufficiently rapid, they may modulate downstream signaling to burst versus tonic firing patterns. Understanding the effects of varying LC patterns of activation is needed for a mechanistic model of LC-induced global remapping.

What were the probable LC patterns with our phasic/tonic manipulations? The glutamate-induced LC burst may have terminated before placement in the open field and would have been followed by silence (Harley and Sara, 1992). However, the IEG mapping patterns induced by glutamate in the $\mathrm{A} / \mathrm{A}$ condition (Fig. 2) are unlike those associated with LC clonidine silencing in the same A/A condition (Fig. 3), suggesting that LC silence is not linked to remapping. A more extended effect of the glutamate burst is probable. NE is elevated for minutes after LC glutamate as indexed by voltammetry (Brun et al., 1993a, b) or microdialysis (Walling et al., 2004). Alternatively, remapping after glutamate might be due to the burst occurring in the larger context of the route and room that preceded placement.

The possible profiles of tonic activator effects should also be considered, particularly given the lack of a change in the network representation. Each would activate differently and be associated with differing side effects. CRF also recruits LC neuropeptide $\mathrm{S}^{+}$ cells (Jüngling et al., 2012). Orexin release co-occurs with glutamate (Huang et al., 2007), which is not mimicked by ORX-A infusion. Tonic activator doses were low and LC rate increases possibly low. However, the similarity in outcomes of the three tonic manipulations is encouraging. Clonidine was also administered at a low dose, but the threshold dose for clonidine LC silencing is significantly lower with bilateral, compared with unilateral, infusions (De Sarro et al., 1987), reinforcing the importance of bilateral LC manipulations.

These experiments further draw attention to regional differences in LC effects across the HPC. The DGS appears especially sensitive to LC as a global remap signal as novel maps were generated in a familiar environment with all treatments. This is consistent with the proposed role of DGS in pattern separation (Neunuebel and Knierim, 2014; Kesner, 2018). When the LC was silenced, only the CA3a/b subregions generated a novel represen- 
tation in a novel environment; DG, CA1, and CA3c expressed the previous familiar map (déjà $v u$ ). This difference in maps between $\mathrm{CA} 3 \mathrm{a} / \mathrm{b}$ and CA1 supports evidence that CA3 has a discontinuous response to input changes unlike CA1 (Guzowski et al., 2004). It is also consistent with a new theoretical framing of CA1 and CA3 function, which argues that CA1 is best characterized as providing "gist" representations, whereas CA3 provides detailed representations (Burke et al., 2018). In the present experiment, the changed details of the novel environment (which were many) may have driven the CA3, whereas a similar box in a similar room supported the gist of the earlier representation with LC activation blocked.

While our data are rodent-based, there is increasing focus on human LC functions, where results similar to those observed in rodents have been reported (Deuker et al., 2016). Pupillometry, and sophisticated MRI techniques, permit indirect monitoring of LC activity. Pupil dilation reflects phasic LC events. There is evidence of representation-modulating effects associated with pupil dilation (Clewett et al., 2018). We have proposed that LC events, in conjunction with brain network activity, generate a priority mechanism for attention and memory (Mather et al., 2016). We argue that there is a particular role for LC projections to the HPC in assigning new networks to mediate encoding that reflects environmental change. Recent evidence demonstrates the $\mathrm{LC}$ is one of the first structures affected in Alzheimer's disease (Mather and Harley, 2016; Weinshenker, 2018) and increases the sense of urgency to improve our understanding of LC functions and their mechanistic underpinnings in relation to memory.

\section{References}

Aston-Jones G, Cohen JD (2005) An integrative theory of locus coeruleusnorepinephrine function: adaptive gain and optimal performance. Annu Rev Neurosci 28:403-450. CrossRef Medline

Aston-Jones G, Rajkowski J, Kubiak P, Alexinsky T (1994) Locus coeruleus neurons in monkey are selectively activated by attended cues in a vigilance task. J Neurosci 14:4467-4480. CrossRef Medline

Aston-Jones G, Rajkowski J, Kubiak P (1997) Conditioned responses of monkey locus coeruleus neurons anticipate acquisition of discriminative behavior in a vigilance task. Neuroscience 80:697-715. CrossRef Medline

Berridge CW, Foote SL (1991) Effects of locus coeruleus activation on electroencephalographic activity in neocortex and hippocampus. J Neurosci 11:3135-3145. CrossRef Medline

Berridge CW, Page ME, Valentino RJ, Foote SL (1993) Effects of locus coeruleus inactivation on electroencephalographic activity in neocortex and hippocampus. Neuroscience 55:381-393. CrossRef Medline

Bouret S, Sara SJ (2005) Network reset: a simplified overarching theory of locus coeruleus noradrenaline function. Trends Neurosci 28:574-582. CrossRef Medline

Brown RA, Walling SG, Milway JS, Harley CW (2005) Locus ceruleus activation suppresses feedforward interneurons and reduces beta-gamma electroencephalogram frequencies while it enhances theta frequencies in rat dentate gyrus. J Neurosci 25:1985-1991. CrossRef Medline

Brun P, Suaud-Chagny MF, Gonon F, Buda M (1993a) Differential effects of desipramine on direct- and sensory-evoked noradrenaline release in thalamic locus coeruleus terminals. Eur J Pharmacol 235:205-210. CrossRef Medline

Brun P, Suaud-Chagny MF, Gonon F, Buda M (1993b) In vivo noradrenaline release evoked in the anteroventral thalamic nucleus by locus coeruleus activation: an electrochemical study. Neuroscience 52:961-972. CrossRef Medline

Bulkin DA, Law LM, Smith DM (2016) Placing memories in context: hippocampal representations promote retrieval of appropriate memories. Hippocampus 26:958-971. CrossRef Medline

Burke SN, Gaynor LS, Barnes CA, Bauer RM, Bizon JL, Roberson ED, Ryan L (2018) Shared functions of perirhinal and parahippocampal cortices: implications for cognitive aging. Trends Neurosci 41:349-359. CrossRef Medline

Carasatorre M, Ochoa-Alvarez A, Velázquez-Campos G, Lozano-Flores C,
Ramírez-Amaya V, Díaz-Cintra SY (2015) Hippocampal synaptic expansion induced by spatial experience in rats correlates with improved information processing in the hippocampus. PLoS One 10:e0132676. CrossRef Medline

Chawla MK, Guzowski JF, Ramirez-Amaya V, Lipa P, Hoffman KL, Marriott LK, Worley PF, McNaughton BL, Barnes CA (2005) Sparse environmentally selective expression of Arc RNA in the upper blade of the rodent fascia dentata by brief spatial experience. Hippocampus 15:579-586. CrossRef Medline

Chay A, Zamparo I, Koschinski A, Zaccolo M, Blackwell KT (2016) Control of $\beta$ AR- and N-methyl-D-aspartate (NMDA) receptor-dependent cAMP dynamics in hippocampal neurons. PLoS Comput Biol 12:e1004735. CrossRef Medline

Chen FJ, Sara SJ (2007) Locus coeruleus activation by foot shock or electrical stimulation inhibits amygdala neurons. Neuroscience 144:472-481. CrossRef Medline

Clément O, Valencia Garcia S, Libourel PA, Arthaud S, Fort P, Luppi PH (2014) The inhibition of the dorsal paragigantocellular reticular nucleus induces waking and the activation of all adrenergic and noradrenergic neurons: a combined pharmacological and functional neuroanatomical study. PLoS One 9:e96851. CrossRef Medline

Clewett DV, Huang R, Velasco R, Lee TH, Mather M (2018) Locus coeruleus activity strengthens prioritized memories under arousal. J Neurosci 38:1558-1574. CrossRef Medline

Cummins Jacklin E, Boughner E, Kent K, Kwiatkowski D, MacDonald T, Leri F (2015) Memory of a drug lapse: role of noradrenaline. Neuropharmacology 99:98-105. CrossRef Medline

Curtis AL, Lechner SM, Pavcovich LA, Valentino RJ (1997) Activation of the locus coeruleus noradrenergic system by intracoerulear microinfusion of corticotropin-releasing factor: effects on discharge rate, cortical norepinephrine levels and cortical electroencephalographic activity. J Pharmacol Exp Ther 281:163-172. Medline

De Sarro GB, Ascioti C, Froio F, Libri V, Nisticò G (1987) Evidence that locus coeruleus is the site where clonidine and drugs acting at alpha 1- and alpha 2-adrenoceptors affect sleep and arousal mechanisms. Br J Pharmacol 90:675-685. CrossRef Medline

Deuker L, Bellmund JL, Navarro Schröder T, Doeller CF (2016) An event map of memory space in the hippocampus. eLife 5:e16534. CrossRef Medline

Florin-Lechner SM, Druhan JP, Aston-Jones G, Valentino RJ (1996) Enhanced norepinephrine release in prefrontal cortex with burst stimulation of the locus coeruleus. Brain Res 742:89-97. CrossRef Medline

Gheidi A, Azzopardi E, Adams AA, Marrone DF (2013) Experiencedependent persistent expression of Zif268 during rest is preserved in the aged dentate gyrus BMC Neurosci 14:100. CrossRef Medline

Guzowski JF, McNaughton BL, Barnes CA, Worley PF (1999) Environmentspecific expression of the immediate-early gene arc in hippocampal neuronal ensembles. Nat Neurosci 2:1120-1124. CrossRef Medline

Guzowski JF, Knierim JJ, Moser EI (2004) Ensemble dynamics of hippocampal regions CA3 and CA1. Neuron 44:581-584. CrossRef Medline

Hagena H, Hansen N, Manahan-Vaughan D (2016) $\beta$-Adrenergic control of hippocampal function: subserving the choreography of synaptic information storage and memory. Cereb Cortex 26:1349-1364. CrossRef Medline

Harley CW (2007) Norepinephrine and the dentate gyrus. Prog Brain Res 163:299-318. CrossRef Medline

Harley CW, Sara SJ (1992) Locus coeruleus bursts induced by glutamate trigger delayed perforant path spike amplitude potentiation in the dentate gyrus. Exp Brain Res 89:581-587. Medline

Hendrickson RC, Raskind MA (2016) Noradrenergic dysregulation in the pathophysiology of PTSD. Exp Neurol 284:181-195. CrossRef Medline

Hirsh R (1974) The hippocampus and contextual retrieval of information from memory: a theory. Behav Biol 12:421-444. CrossRef Medline

Huang HP, Wang SR, Yao W, Zhang C, Zhou Y, Chen XW, Zhang B, Xiong W, Wang LY, Zheng LH, Landry M, Hökfelt T, Xu ZQ, Zhou Z (2007) Long latency of evoked quantal transmitter release from somata of locus coeruleus neurons in rat pontine slices. Proc Natl Acad Sci U S A 104: 1401-1406. CrossRef Medline

Hunsaker MR, Kesner RP (2008) Evaluating the differential roles of the dorsal dentate gyrus, dorsal CA3, and dorsal CA1 during a temporal ordering for spatial locations task. Hippocampus 18:955-964. CrossRef Medline 
Jüngling K, Liu X, Lesting J, Coulon P, Sosulina L, Reinscheid RK, Pape HC (2012) Activation of neuropeptide S-expressing neurons in the locus coeruleus by corticotropin-releasing factor. J Physiol 590:3701-3717. CrossRef Medline

Karlsson MP, Frank LM (2008) Network dynamics underlying the formation of sparse, informative representations in the hippocampus. J Neurosci 28:14271-14281. CrossRef Medline

Kempadoo KA, Mosharov EV, Choi SJ, Sulzer D, Kandel ER (2016) Dopamine release from the locus coeruleus to the dorsal hippocampus promotes spatial learning and memory. Proc Natl Acad Sci U S A 113: 14835-14840. CrossRef Medline

Kesner RP (2018) An analysis of dentate gyrus function (an update). Behav Brain Res 354:84-91. CrossRef Medline

Kiyashchenko LI, Mileykovskiy BY, Lai YY, Siegel JM (2001) Increased and decreased muscle tone with orexin (hypocretin) microinjections in the locus coeruleus and pontine inhibitory area. J Neurophysiol 85:20082016. CrossRef Medline

Kourtesis I, Kasparov S, Verkade P, Teschemacher AG (2015) Ultrastructural correlates of enhanced norepinephrine and neuropeptide $Y$ cotransmission in the spontaneously hypertensive rat brain. ASN Neuro 7:1759091415610115. Medline

Liberzon I, Abelson JL (2016) Context processing and the neurobiology of post-traumatic stress disorder. Neuron 92:14-30. CrossRef Medline

Lundberg JM, Rudehill A, Sollevi A, Fried G, Wallin G (1989) Co-release of neuropeptide $\mathrm{Y}$ and noradrenaline from pig spleen in vivo: importance of subcellular storage, nerve impulse frequency and pattern, feedback regulation and resupply by axonal transport. Neuroscience 28:475-486. CrossRef Medline

Maple A, Lackie RE, Elizalde DI, Grella SL, Damphousse CC, Xa C, Gallitano AL, Marrone DF (2017) Attenuated late-phase arc transcription in the dentate gyrus of mice lacking Egr3. Neural Plast 2017:6063048. CrossRef Medline

Maren S, Phan KL, Liberzon I (2013) The contextual brain: implications for fear conditioning, extinction and psychopathology. Nat Rev Neurosci 14:417-428. CrossRef Medline

Marrone DF, Satvat E, Odintsova IV, Gheidi A (2014) Dissociation of spatial representations within hippocampal region CA3. Hippocampus 24: 1417-1420. CrossRef Medline

Mather M, Harley CW (2016) The locus coeruleus: essential for maintaining cognitive function and the aging brain. Trends Cogn Sci 20:214-226. CrossRef Medline

Mather M, Clewett D, Sakaki M, Harley CW (2016) Norepinephrine ignites local hotspots of neuronal excitation: how arousal amplifies selectivity in perception and memory. Behav Brain Sci 39:e200. CrossRef Medline

McCall JG, Al-Hasani R, Siuda ER, Hong DY, Norris AJ, Ford CP, Bruchas MR (2015) CRH engagement of the locus coeruleus noradrenergic system mediates stress-induced anxiety. Neuron 87:605-620. CrossRef Medline

McKenzie S, Eichenbaum H (2011) Consolidation and reconsolidation: two lives of memories? Neuron 71:224-233. CrossRef Medline

Moita MA, Rosis S, Zhou Y, LeDoux JE, Blair HT (2004) Putting fear in its place: remapping of hippocampal place cells during fear conditioning. J Neurosci 24:7015-7023. CrossRef Medline

Morrison FG, Ressler KJ (2014) From the neurobiology of extinction to improved clinical treatments. Depress Anxiety 31:279-290. CrossRef Medline

Neunuebel JP, Knierim JJ (2014) CA3 retrieves coherent representations from degraded input: direct evidence for CA3 pattern completion and dentate gyrus pattern separation. Neuron 81:416-427. CrossRef Medline

O'Keefe J, Nadel L (1978) The hippocampus as a cognitive map. Oxford: Clarendon.

Paxinos G, Watson C (2013) The rat brain in stereotaxic coordinates 7th edition. Cambridge, MA: Academic Press.

Rajkowski J, Kubiak P, Aston-Jones G (1994) Locus coeruleus activity in monkey: phasic and tonic changes are associated with altered vigilance. Brain Res Bull 35:607-616. CrossRef Medline

Ramirez-Amaya V, Angulo-Perkins A, Chawla MK, Barnes CA, Rosi S (2013) Sustained transcription of the immediate early gene arc in the dentate gyrus after spatial exploration. J Neurosci 33:1631-1639. CrossRef Medline
Reid AT, Harley CW (2010) An associativity requirement for locus coeruleus-induced long-term potentiation in the dentate gyrus of the urethane-anesthetized rat. Exp Brain Res 200:151-159. CrossRef Medline

Sakamoto H, Fukuda S, Minakawa Y, Sawamura S (2013) Clonidine induces sedation through acting on the perifornical area and the locus coeruleus in rats. J Neurosurg Anesthesiol 25:399-407. CrossRef Medline

Salgado H, Köhr G, Treviño M (2012) Noradrenergic 'tone' determines dichotomous control of cortical spike-timing-dependent plasticity. Scientific Reports 2:417. CrossRef

Sara SJ, Vankov A, Hervé A (1994) Locus coeruleus-evoked responses in behaving rats: a clue to the role of noradrenaline in memory. Brain Res Bull 35:457-465. CrossRef Medline

Sheynin J, Liberzon I (2017) Circuit dysregulation and circuit-based treatments in posttraumatic stress disorder. Neurosci Lett 649:133-138. CrossRef Medline

Skinner DM, Martin GM, Wright SL, Tomlin J, Odintsova IV, Thorpe CM, Harley CW, Marrone DF (2014) Hippocampal spatial mapping and the acquisition of competing responses. Hippocampus 24:396-402. CrossRef Medline

Smith CC, Greene RW (2012) CNS dopamine transmission mediated by noradrenergic innervation. J Neurosci 32:6072-6080. CrossRef Medline

Stone EA, Zhang Y, Carr KD (1995) Massive activation of c-fos in forebrain after mechanical stimulation of the locus coeruleus. Brain Res Bull 36:7780. CrossRef Medline

Takeuchi T, Duszkiewicz AJ, Sonneborn A, Spooner PA, Yamasaki M, Watanabe M, Smith CC, Fernández G, Deisseroth K, Greene RW, Morris RG (2016) Locus coeruleus and dopaminergic consolidation of everyday memory. Nature 537:357-362. CrossRef Medline

Teyler TJ, DiScenna P (1986) The hippocampal memory indexing theory. Behav Neurosci 100:147-154. CrossRef Medline

Teyler TJ, Rudy JW (2007) The hippocampal indexing theory and episodic memory: updating the index. Hippocampus 17:1158-1169. CrossRef Medline

Timmermans PB, Brands A, van Zwieten PA (1977) Lipophilicity and brain disposition of clonidine and structurally related imidazolidines. Naunyn Schmiedebergs Arch Pharmacol 300:217-226. CrossRef Medline

Tonegawa S, Liu X, Ramirez S, Redondo R (2015) Memory engram cells have come of age. Neuron 87:918-931. CrossRef Medline

Trudeau LE (2004) Glutamate co-transmission as an emerging concept in monoamine neuron function. J Psychiatry Neurosci 29:296-310. Medline

Vazey EM, Moorman DE, Aston-Jones G (2018) Phasic locus coeruleus activity regulates cortical encoding of salience information. Proc Natl Acad Sci U S A 115:E9439-E9448. CrossRef Medline

Vila-Porcile E, Xu ZQ, Mailly P, Nagy F, Calas A, Hökfelt T, Landry M (2009) Dendritic synthesis and release of the neuropeptide galanin: morphological evidence from studies on rat locus coeruleus neurons. J Comp Neurol 516:199-212. CrossRef Medline

Wagatsuma A, Okuyama T, Sun C, Smith LM, Abe K, Tonegawa S (2018) Locus coeruleus input to hippocampal CA3 drives single-trial learning of a novel context. Proc Natl Acad Sci U S A 115:E310-E316. CrossRef Medline

Walling SG, Harley CW (2004) Locus ceruleus activation initiates delayed synaptic potentiation of perforant path input to the dentate gyrus in awake rats: a novel beta-adrenergic- and protein synthesis-dependent mammalian plasticity mechanism. J Neurosci 24:598-604. CrossRef Medline

Walling SG, Nutt DJ, Lalies MD, Harley CW (2004) Orexin-A infusion in the locus ceruleus triggers norepinephrine (NE) release and NE-induced long-term potentiation in the dentate gyrus. J Neurosci 24:7421-7426. CrossRef Medline

Weinshenker D (2018) Long road to ruin: noradrenergic dysfunction in neurodegenerative disease. Trends Neurosci 41:211-223. CrossRef Medline

Wilcox BJ, Unnerstall JR (1990) Identification of a subpopulation of neuropeptide Y-containing locus coeruleus neurons that project to the entorhinal cortex. Synapse 6:284-291. CrossRef Medline

Wilson MA, McNaughton BL (1993) Dynamics of the hippocampal ensemble code for space. Science 261:1055-1058. CrossRef Medline 